\title{
Treatment of hazardous waste landfill leachate using Fenton oxidation process
}

\author{
Pradeep Kumar Singa ${ }^{l *}$, Mohamed Hasnain $\mathrm{Isa}^{l}$, Yeek-Chia $\mathrm{Ho}^{l}$, and Jun-Wei $\mathrm{Lim}^{2}$ \\ ${ }^{1}$ Department of Civil \& Environmental Engineering, Universiti Teknologi PETRONAS, 32610 \\ Bandar Seri Iskandar, Malaysia \\ ${ }^{2}$ Department of Fundamental \& Applied Sciences, Universiti Teknologi PETRONAS, 32610 Bandar \\ Seri Iskandar, Malaysia
}

\begin{abstract}
The efficiency of Fenton's oxidation was assessed in this study for hazardous waste landfill leachate treatment. The two major reagents, which are generally employed in Fenton's process are $\mathrm{H}_{2} \mathrm{O}_{2}$ as oxidizing agent and $\mathrm{Fe}^{2+}$ as catalyst. Batch experiments were conducted to determine the effect of experimental conditions viz., reaction time, molar ratio, and Fenton reagent dosages, which are significant parameters that influence the degradation efficiencies of Fenton process were examined. It was found that under the favorable experimental conditions, maximum COD removal was $56.49 \%$. The optimum experimental conditions were $\mathrm{pH}=3, \mathrm{H}_{2} \mathrm{O}_{2} / \mathrm{Fe}^{2+}$ molar ratio $=3$ and reaction time $=150$ minutes. The optimal amount of hydrogen peroxide and iron were $0.12 \mathrm{~mol} / \mathrm{L}$ and $0.04 \mathrm{~mol} / \mathrm{L}$ respectively. High dosages of $\mathrm{H}_{2} \mathrm{O}_{2}$ and iron resulted in scavenging effects on $\mathrm{OH} \bullet$ radicals and lowered degradation efficiency of organic compounds in the hazardous waste landfill leachate.
\end{abstract}

\section{Introduction}

Globally, engineered landfill is practiced as the easiest and most economical method of disposing municipal and hazardous solid waste. Generation of leachate has been encountered as a significant issue in landfilling, which contaminates surface and subsurface water leading to the mortality of aquatic flora and fauna. Leachate is a concentrated wastewater generated by passage of rainwater through various layers of landfill. The various factors on which leachate characteristics depends include site hydrology, landfill age, temperature, landfill depth, refuse composition and moisture content [1].

Reverse osmosis, Biological treatment, chemical oxidation, chemical precipitation, activated carbon adsorption, electrochemical oxidation and ion exchange are the various treatment techniques which have been employed for the removal of recalcitrant organic compounds from landfill leachate [2]. Many researchers have reported the chemical treatment techniques, which uses the oxidizing agents viz; Fenton's process, photo-Fenton, UV-Visible light or ozone for leachate treatment. These treatment methods are collectively known as advanced oxidation processes (AOPs), which employ hydroxyl radicals as a strong oxidation agent. Fenton and associated reactions involve reactions of iron with

\footnotetext{
* Corresponding author: pmsinga@gmail.com
} 
hydrogen peroxide, which form oxygen species that oxidize organic or inorganic compounds. Fenton process was named after H.J.H Fenton in 1894 and later he arrived at the conclusion that hydrogen peroxide could be activated by ferrous as catalyst to oxidize tartaric acid. Past few years, the significance of hydroxyl radical's reactions has been identified and around 1700 rate constants for hydroxyl reactions with inorganic and organic compounds in aqueous solutions have been reported. Recently, Fenton process was vastly used in the treatment of various industrial effluents for the degradation of several hazardous organic compounds [3]. In Fenton's reagents there are two constituents; a catalytic species $\left(\mathrm{Fe}^{2+}\right)$ and a strong oxidant $\left(\mathrm{H}_{2} \mathrm{O}_{2}\right)$ [3]. The Fenton oxidation process has been commonly employed to degrade refractory organic compounds from leachate as a pre and/or post treatment method.

The definition of Fenton's process can be stated as the catalytic production of hydroxyl radicals $(\mathrm{OH} \bullet)$ arising from a series of reactions between $\mathrm{Fe}^{2+}$ ions and $\mathrm{H}_{2} \mathrm{O}_{2}$.

Hydroxyl radicals are produced by catalysis of hydrogen peroxide by ferrous ions [4]:

$$
\mathrm{Fe}^{2+}+\mathrm{H}_{2} \mathrm{O}_{2} \rightarrow \mathrm{Fe}^{3+}+\mathrm{OH}^{-}+\mathrm{OH} \bullet
$$

$\mathrm{Fe}^{3+}$ is again converted to $\mathrm{Fe}^{2+}$

$$
\mathrm{H}_{2} \mathrm{O}_{2}+\mathrm{Fe}^{3+} \rightarrow \mathrm{Fe}^{2+}+\mathrm{HO}+\mathrm{H}^{+}
$$

Additionally, hydroxyl radicals rapidly destroy ferrous ions.

$$
\mathrm{Fe}^{2+}+\mathrm{OH} \bullet \rightarrow \mathrm{Fe}^{3+}+\mathrm{OH}^{-}
$$

Thereafter the organic matter would be degraded by hydroxyl radicals generated in the landfill leachate:

$$
\begin{aligned}
& \mathrm{RH}+\mathrm{OH} \bullet \rightarrow \mathrm{H}_{2} \mathrm{O}+\mathrm{R} \bullet \\
& \mathrm{R} \bullet+\mathrm{Fe}^{3+} \rightarrow \mathrm{R}^{+}+\mathrm{Fe}^{2+}
\end{aligned}
$$

Hence, sufficient of ferrous ion is required to retain the moderate hydroxyl radicals' reduction. But this leads to production of high volume of ferric hydroxide sludge in neutralization step of Fenton process, which has to be separated and disposed. In the Fenton's reaction each of the factors are optimized to boost the reaction between the hydroxyl radicals and the pollutants [5]. Fenton's reaction has some advantages as compared to other AOPs. The advantages of this process include easy implementation and operation, low cost of reagents, high efficiency, lower production of harmful by-products and no requirement of energy for $\mathrm{H}_{2} \mathrm{O}_{2}$ activation. Since Fenton's process has the above mentioned advantages, it has been used in treatment of various wastewaters and also for treatment of landfill leachate. In order to make the biological treatment economical Fenton's process was used as a post-treatment instead of pre-treatment in the treatment of landfill leachate. By combining the biological and chemical treatment methods COD removal efficiency can be enhanced [6].

Nevertheless, this process also has a few disadvantages, which include fast consumption of $\mathrm{Fe}^{2+}$ relative to its rate of regeneration, generation of sludge that requires post treatment, narrow $\mathrm{pH}$ range to operate, the complexity of few iron species and the possible waste of oxidants. $\mathrm{H}_{2} \mathrm{O}_{2}$ is eco-friendly, as it gradually breaks up into $\mathrm{O}_{2}$ and $\mathrm{H}_{2} \mathrm{O} . \mathrm{Fe}^{2+}$ is nontoxic in nature, highly available and can be easily removed from water, which makes it the most frequently used transition metal for Fenton's oxidation process. The main objective of this experiment is to determine the effect of significant operating conditions viz., reaction time, molar ratio and Fenton's reagent dosages on COD removal from hazardous waste landfill 
leachate using Fenton's oxidation process [7]. The outcomes of this research might be useful for increasing COD removal efficiency using Fenton oxidation in the field.

\section{Materials and methods}

\subsection{Sampling}

Hazardous waste landfill leachate samples were obtained from Kualiti Alam, Malaysia. Approximately 100 tons of hazardous waste is received by this facility per day and an average of $150 \mathrm{~m}^{3}$ of leachate is generated per day. Table 1 presents the characteristics of the hazardous waste leachate. The samples were kept in a cold room at $4^{\circ} \mathrm{C}$ until use. All parameters were measured according to the Standard Methods for the Examination of Water and Wastewater (APHA, AWWA, WEF, 1992).

Table 1. Leachate characteristics.

\begin{tabular}{|c|c|c|c|c|c|c|}
\hline Parameter & $\mathrm{pH}$ & BOD5 & COD & $\begin{array}{c}\text { Suspended } \\
\text { solids }\end{array}$ & Nitrates & $\mathrm{NH}_{3}-\mathrm{N}$ \\
\hline Value (mg/L)* & 9.53 & 960 & 3715 & 1168 & 23 & 1668 \\
\hline
\end{tabular}

*All the values are in $\mathrm{mg} / \mathrm{L}$ except $\mathrm{pH}$

\subsection{Fenton Experiments}

Batch experiments were conducted on Fenton oxidation of hazardous waste landfill leachate using beakers of $500 \mathrm{ml}$ capacity. $\mathrm{H}_{2} \mathrm{SO}_{4}$ was used for adjusting $\mathrm{pH}$ to 3 . In every run, desired amounts of $\mathrm{FeSO}_{4} .7 \mathrm{H}_{2} \mathrm{O}$ and $\mathrm{H}_{2} \mathrm{O}_{2}(30 \%)$ were added to determine the optimum dosages of the reagents. All experiments were carried out at atmospheric pressure and room temperature. Fenton oxidation has better efficiency in acidic medium hence initial $\mathrm{pH}$ of leachate was reduced to 3 using $1 \mathrm{M}$ sulphuric acid. A magnetic stirrer was used to stir the leachate thoroughly. After completion of each experiment, the $\mathrm{pH}$ was increased above 10 by addition of $\mathrm{NaOH}$ to suppress the reaction. The degradation efficiency of organics via oxidation ceases at high $\mathrm{pH}$ values [8]. The sample was kept undisturbed for half an hour at the end of the experiment to allow the sludge to settle down and the supernatant was collected for COD measurement.

\subsection{Analytical methods}

COD analyses were carried out by using a DR/5000 spectrophotometer. All solutions were prepared with distilled water. Hach $\mathrm{pH}$ meter was made use of to measure the $\mathrm{pH}$. In order to get the accuracy in the results the experiments were conducted in triplicate. Percentage removal was determined by using the equation 6 .

$$
R=\left(\frac{C o-C}{C o}\right) * 100
$$

Where $\mathrm{Co}=\mathrm{COD}$ before treatment and $\mathrm{C}=\mathrm{COD}$ after treatment. 


\section{Results and discussions}

\subsection{Optimum molar ratio}

$\mathrm{H}_{2} \mathrm{O}_{2}$ and $\mathrm{Fe}^{2+}$ are two important reagents in Fenton process that govern the efficiency and cost of operation. It is essential to find the optimum $\mathrm{H}_{2} \mathrm{O}_{2} / \mathrm{Fe}^{2+}$ molar ratio to enhance the efficiency of the process. $\mathrm{H}_{2} \mathrm{O}_{2}$ and $\mathrm{Fe}^{2+}$ play a vital role in the degradation of organic compounds by Fenton process; understanding the phenomenon helps in determination of the optimum dosages of Fenton reagents, as they are utilized to generate the hydroxyl radicals required to degrade organic compounds (Equation 7).

$$
\text { Organic substances }+\mathrm{OH} \bullet \rightarrow \text { Oxidation Products }
$$

It is required to pay additional attention on $\mathrm{Fe}^{2+}$ and $\mathrm{H}_{2} \mathrm{O}_{2}$ dosages, as high dosages of these reagents lead to generation of undesired $\mathrm{OH} \bullet$ radicals which has scavenging reactions leading to decrease in the process efficiency [9]. To determine the optimum $\mathrm{H}_{2} \mathrm{O}_{2} / \mathrm{Fe}^{2+}$ molar ratio, various $\mathrm{H}_{2} \mathrm{O}_{2} / \mathrm{Fe}^{2+}$ molar ratios i.e., 1, 2, 3, 4, 5, 6 and 7 were tested as shown in Fig. 1. The maximum removal of COD was $29.95 \%$ at $\mathrm{H}_{2} \mathrm{O}_{2} / \mathrm{Fe}^{2+}$ molar ratio of 3 and $\mathrm{Fe}^{2+}$ dose of $0.01 \mathrm{~mol} / \mathrm{L}$.

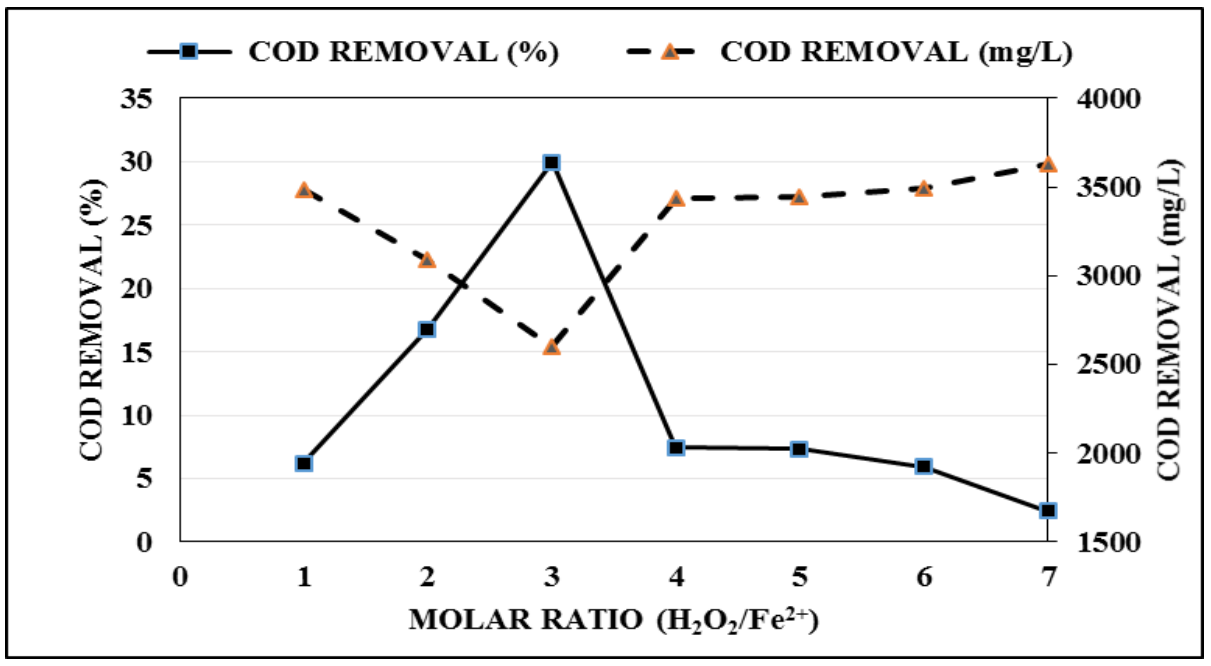

Fig. 1. Molar ratio vs $\mathrm{COD}$ removal $\left(\mathrm{Fe}^{2+}=0.01 \mathrm{~mol} \mathrm{~L}^{-1}, \mathrm{pH}=3\right.$, time $\left.=60 \mathrm{~min}\right)$.

It seems that higher hydrogen peroxide doses result in scavenging effect on hydroxyl radicals (Equation 8).

$$
\mathrm{H}_{2} \mathrm{O}_{2}+\mathrm{OH}^{\cdot} \rightarrow \mathrm{H}_{2} \mathrm{O}+\mathrm{HO}_{2}{ }_{2}
$$

The produced hydro-peroxyl radical has weak oxidizing potential in comparison with hydroxyl radicals. In addition, the high dosages of $\mathrm{H}_{2} \mathrm{O}_{2}$ leads to its auto-decomposition forming oxygen and water, and also when the hydroxyl radicals recombine, results in the reduction of concentration of hydroxyl radicals and in addition reduces compound removal efficiency. COD removal efficiency was reduced as a result of scavenging effect of excess $\mathrm{Fe}^{2+}$ when the molar ratio was lower than 3 as shown in equation 3. Hence when a high amount of $\mathrm{Fe}^{2+}$ is available, $\mathrm{Fe}^{2+}$ and organic compounds compete to react with hydroxyl 
radicals. Thus, $\mathrm{Fe}^{2+}$ exhausts hydroxyl radical, finally leading to reduced COD removal efficiency as shown in Equation 3 [10].

Consequently, the excess $\mathrm{Fe}^{2+}$ dosage and the less quantities of hydroxyl radicals are present to oxidize organic matters. Additional of $\mathrm{Fe}^{3+}$ produced react with hydrogen peroxide to produce $\mathrm{Fe}^{2+}$ and hydroperoxyl radicals. Hence, molar ratio 3 was selected as the optimum molar ratio. On the other hand, the concentrations of Fenton reagents that can be found in literature for treatment of leachate are vastly different. As an example Lopez et al. [6] reported optimum molar ratio of $\mathrm{H}_{2} \mathrm{O}_{2}$ to $\mathrm{Fe}^{2+}$ of $20: 1$, whereas optimum molar ratio was 1.5 as reported by Zhang et al. [11]. It may be due to the variations in the characteristics of leachate, which lead to the vast variations in optimal ratios of $\mathrm{H}_{2} \mathrm{O}_{2}$ to $\mathrm{Fe}^{2+}$.

\subsection{Optimum reaction time}

The impact of reaction time on Fenton oxidation was investigated to find the optimum duration of reaction. The reaction time was starting from 30 minutes and varied up to 240 minutes with an interval of 30 minutes each. The initial $\mathrm{pH}$ was adjusted to 3 and the dosage of $\mathrm{H}_{2} \mathrm{O}_{2}$ and $\mathrm{Fe}^{2+}$ were kept constant at $0.03 \mathrm{~mol} \mathrm{~L}^{-1}$ and $0.01 \mathrm{~mol} \mathrm{~L}^{-1}$, respectively. Fig. 2 shows that COD removal reached equilibrium at $150 \mathrm{~min}$ with COD removal of $40.98 \%$. There was no substantial change in COD removal efficiency with further increase in the reaction time.

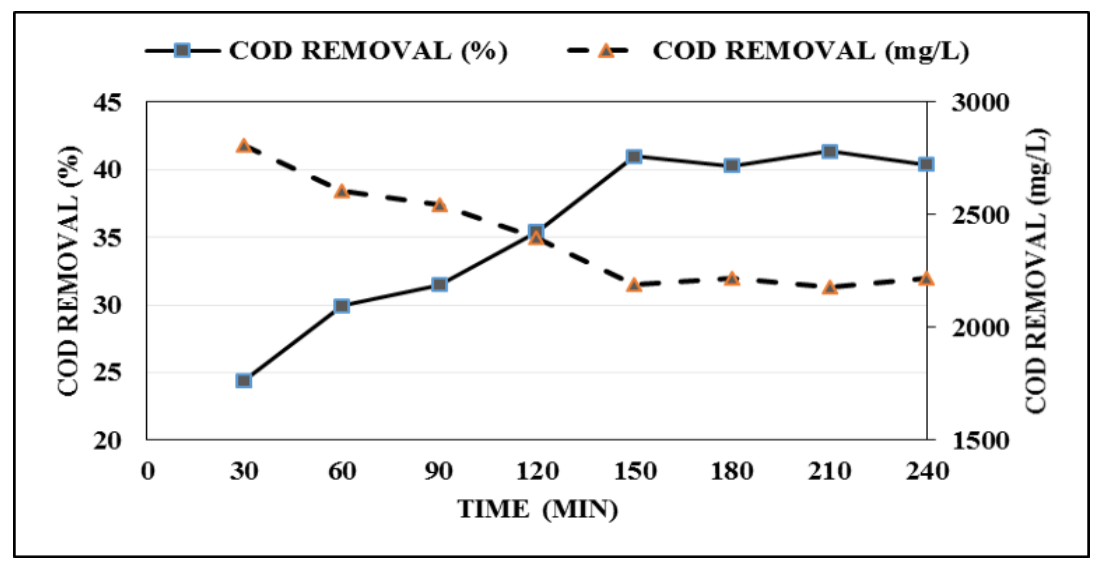

Fig. 2. Reaction time vs COD removal $\left(\mathrm{pH}=3, \mathrm{H}_{2} \mathrm{O}_{2} / \mathrm{Fe}^{2+}=0.03 \mathrm{~mol} \mathrm{~L}-1 / 0.01 \mathrm{~mol} \mathrm{~L}^{-1}\right)$.

\subsection{Optimum Fenton reagents dosages}

To evaluate the correlation between the reagents dosage and COD removal efficiencies, a series of experiments were conducted at $\mathrm{H}_{2} \mathrm{O}_{2} / \mathrm{Fe}^{2+}$ molar ratio and reaction time of 3 and 150 minutes respectively, and with varying dosages of $\mathrm{H}_{2} \mathrm{O}_{2}$ and iron.

Fig. 3 shows that there is gradual increase in COD removal percentage as Fenton reagent dosages are increased. Highest COD removal percentage was $56.49 \%$ at optimum dosage of $\mathrm{H}_{2} \mathrm{O}_{2} / \mathrm{Fe}^{2+}=0.12 \mathrm{~mol} \mathrm{~L}-1 / 0.04 \mathrm{~mol} \mathrm{~L}^{-1}$. Further increase in the dosages lead to decrease in the COD removal efficiency. This can be explained by taking in to account that the hydroxyl radicals might have been scavenged by the reaction with higher dosages of $\mathrm{H}_{2} \mathrm{O}_{2}$ and $\mathrm{Fe}^{2+}$ as shown in Equations 3 \& 8. From the results it can be concluded that the highest COD removal can be attained when both $\mathrm{H}_{2} \mathrm{O}_{2}$ and $\mathrm{Fe}^{2+}$ are dosed appropriately. 


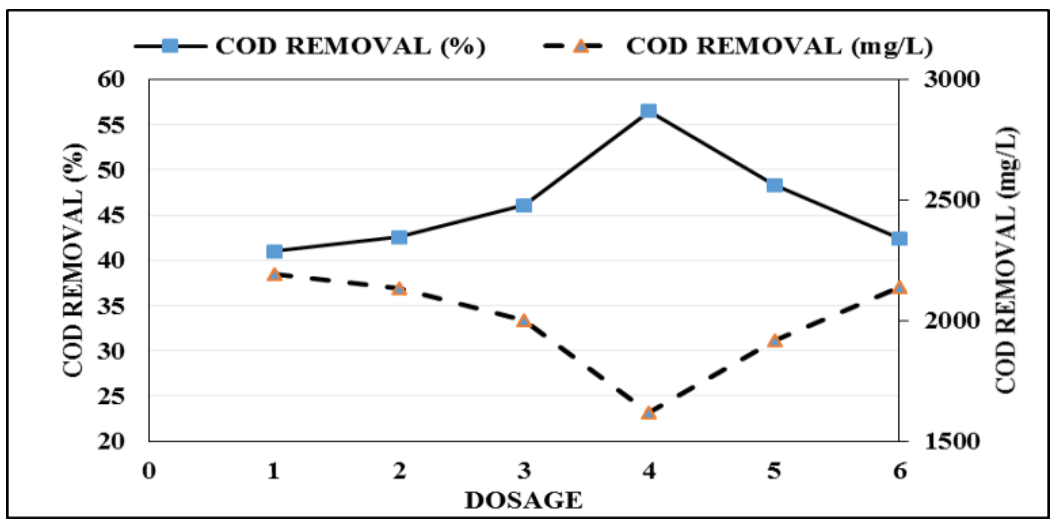

Fig. 3. Dosage of $\mathrm{H}_{2} \mathrm{O}_{2} / \mathrm{Fe}^{2+}$ vs $\mathrm{COD}$ removal $(\mathrm{pH}=3$, Reaction time $=150 \mathrm{~min})$.

Table 2. Optimum dosage.

\begin{tabular}{|c|c|c|c|c|c|c|}
\hline Dosage & $\mathbf{1}$ & $\mathbf{2}$ & $\mathbf{3}$ & $\mathbf{4}$ & $\mathbf{5}$ & $\mathbf{6}$ \\
\hline $\mathrm{H}_{2} \mathrm{O}_{2}$ & 0.03 & 0.06 & 0.09 & 0.12 & 0.15 & 0.18 \\
\hline $\mathrm{Fe}^{2+}$ & 0.01 & 0.02 & 0.03 & 0.04 & 0.05 & 0.06 \\
\hline
\end{tabular}

\section{Conclusions}

Fenton oxidation process seems to be a suitable treatment technique for degradation of organic compounds from hazardous waste landfill leachate. Highest COD removal of $56.49 \%$ was obtained under optimum operating conditions. The optimum operating conditions were molar ratio $\left(\mathrm{H}_{2} \mathrm{O}_{2} / \mathrm{Fe}^{2+}\right)$ of $3.0, \mathrm{pH} 3$ and reaction time of 150 minutes. The optimum dosage of hydrogen peroxide and ferrous sulphate were $0.12 \mathrm{~mol} \mathrm{~L}^{-1}$ and $0.04 \mathrm{~mol}$ $\mathrm{L}^{-1}$ respectively.

\section{References}

1. S. Renou, J. G. Givaudan, S. Poulain, F. Dirassouyan, P. Moulin, J. Hazard. Mat. 150(3), 468-493, (2008)

2. Y. Deng and J. D. Englehardt, A. Babuponnusami, K. Muthukumar, J. Environ. Chem. Eng., 2(1), 557-572, (2014)

3. N. Wang, T. Zheng, G. Zhang, P. Wang, Biochem. Pharmacol. 4(1), 762-787, (2016)

4. A. R. Ribeiro, O. C. Nunes, M. F. R. Pereira, A. M. T. Silva, Environ. Int., 75, 33-51, (2015).

5. A. Lopez, M. Pagano, A. Volpe, A. Claudio, D. Pinto, Chemosphere 54, 1005-1010, (2004)

6. F.J. Beltrán, M. González, F. J. Rivas, P. Alvarez, Water, Air, and Soil Pollution 105, 685-700 (1998)

7. S. S. A. Amr, H. A. Aziz, Waste Manag. 32(9), 1693-1698, (2012)

8. S. K. Singh, W. Z. Tang, G. Tachiev, Waste Manag. 33(10), 2116-2122, (2013)

9. S.Mohajari, H.Aziz, M. Isa, M.Bashir, L.Mohajari, M. Adlan, Journal of Environ Sci and Health, (2010)

10. H. Zhang, H. Jin, C. Huang, Journal of Hazard. Mat. 125(1-3), 166-174, (2005). 